\section{Trial and error}

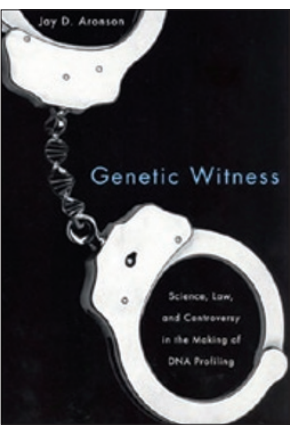

\section{Genetic Witness: Science, Law, and Controversy in the Making of DNA Profiling}

\author{
By Jay D. Aronson
}

Rutgers University Press, 2007

270 pp., paperback, $\$ 23.95$

ISBN 978-0-8135-4188-4

Reviewed by Alan Packer

The use of DNA profiling in the criminal justice system, whether to convict or to exonerate, is now routine, as every judge, lawyer and prime-time television viewer will attest. But it wasn't always so, and not even in the recent past. Private companies began offering their services to police departments in the mid-1980s, with some initial success, but within two or three years, prosecutors who were relying on this evidence were facing significant opposition in the courtroom from alert defense attorneys and a small group of skeptical scientists who helped to educate them. In his thorough and surprisingly entertaining account of what came to be known as 'The DNA Wars', Jay D. Aronson guides the reader through the controversial road to acceptance of new science in the courtroom, and in so doing, he sheds light on a significant episode in the recent history of science.

Aronson is an assistant professor of history at Carnegie Mellon University, but he proves adept at explaining the science of DNA profiling. The use of DNA as a unique identifier became a practical possibility in 1984, with the work on variable number tandem repeats by Alec Jeffreys and colleagues in the UK. Aronson takes the uninitiated reader through the basics of gel electrophoresis and Southern blotting, singlelocus and multi-locus probes, Hardy-Weinberg equilibrium and population substructure. He then shows how DNA profiling migrated to the United States on the wings of two companies, Cellmark Diagnostics and Lifecodes Corporation, which were eager to apply the technology to this potentially large market in paternity and forensic cases.

The book then enters the courtroom, as Aronson follows a series of 'admissibility hearings', which are pre-trial hearings in the US criminal justice system that are designed to determine whether evidence based on new scientific principles or methods can be introduced during the trial. Until 1993, admissibility was governed by the 'Frye rule', which emerged from a 1923 case that tasked judges with determining that a scientific principle is "sufficiently established to have gained general acceptance in the particular field in which it belongs." And there, of course, is the rub. As Aronson shows, this is a tall order for a judge, who may have little or no background in molecular biology and genetics. Moreover, the assessment of "general acceptance" is one of those precepts, like "reasonable doubt," that constitute the Rorschach tests of
American jurisprudence. As prosecutors were the first to try to exploit DNA profiling, they had the advantage in such hearings and called upon eminent scientists such as David Housman and Richard Roberts to drive home the point that Southern blotting was a standard approach being used successfully in labs all over the world. On the basis of the limited information that these prosecutors and scientists received from the companies doing the work, it was not immediately obvious why the technology couldn't be transferred to a forensic context.

Defense attorneys were desperate, imagining the response of a jury to the news that DNA found at a crime scene matched that of their client, with a probability against a random match of a billion to 1 . The turning point came when two such attorneys, Barry Scheck and Peter Neufeld, took over the defense of Joseph Castro, a Bronx man who was on trial for two murders he had allegedly committed in early 1987. Neufeld was invited to participate in a conference on forensic DNA analysis at the Cold Spring Harbor Laboratory's Banbury Center, where he heard Eric Lander deliver a skeptical talk on DNA profiling. After further discussion, Lander agreed to serve as a consultant to the defense, and he ultimately served as a critical witness. Prompted by Lander to request all of the raw data from Lifecodes (the company that carried out the profiling in the Castro case), Scheck and Neufeld systematically picked apart the prosecution's claims that blood found on their client's watch was a match to the blood of one of the victims. In what is arguably the dramatic centerpiece of Genetic Witness, Aronson shows how Scheck, Neufeld and Lander discovered glaring errors in procedure: extra bands on the autoradiogram were ignored, standard methodology used to assess band matches was ignored, and even the probe selected to determine the sex of the individual was shown to be the subject of internal confusion at Lifecodes. The judge in the case declared the DNA evidence "inadmissible as a matter of law," and the ruling opened the way for additional challenges in such hearings. The most prominent of the follow-up challenges involved defense witnesses such as Dan Hartl and Richard Lewontin, who argued on populationgenetic grounds that the estimates provided by the companies as to the probability of a random match were likely vast underestimates, and would remain so without an empirical assessment of genetic substructure in US populations.

Aronson makes clear that the scientists testifying for the defense were not necessarily arguing against DNA profiling in principle; rather, they were concerned that in the context of potentially contaminated crime scenes, the necessary precautions would have to go substantially beyond those carried out in the average molecular biology lab. In Aronson's view, the adversarial system of the courtroom-and in particular the defense attorneys_-provided a critical level of quality control for a technology that would prove to be powerful and essential once potential flaws were brought to light. Implicit in this argument is the suggestion that the initial difficulties faced by DNA profiling should serve as a warning to private enterprise generally as it brings genetic technologies to the marketplace. In American life, the legal system is ever at the ready, and it should be clear by now that companies offering genetic services to public organizations or to private individuals should be prepared to justify their protocols and claims in court. 